\title{
OPTIMISING CONSTRAINTS OF 'CAVE SYNDROME’ FEAR OF COMING BACK TO NORMALITY
}

\author{
Mohamed Buheji ${ }^{1}$ and Dunya Ahmed ${ }^{2}$ \\ ${ }^{1}$ Founder- International Institute of Inspiration Economy, Bahrain \\ ${ }^{2}$ University of Bahrain \& Bahrain Inspiration Economy Society, Bahrain
}

\begin{abstract}
At the beginning of the Covid-19 pandemic, people found it to be challenging to deal with what was called the new normal. However, soon they got used to it and recognised some of its advantages. Many started to see some hidden opportunities in this pandemic, especially was a good experience to re-evaluate lifestyle and take the best of it. As many governments and institutes are starting to adapt to the new normal, the fear of getting back to many pre-pandemic life norms and routines is very high.

This paper investigates the type of fears, as a result of going back to normality, by using the method of integrative study. The type of fear is specified in order to define mechanisms for its alleviation. The recommendation here is to create balanced solutions or environments that compensate for the need for pre-and post-pandemic routines or resilient transformation plans. However, this recommendation needs to be piloted in different communities and in a different environment to overcome the limitations of its practicality, taking into consideration the variations of fear according to the demographics and the functionality.
\end{abstract}

Key words: COVID-19 Pandemic, Post New normal, Fear, Cave Syndrome, Cultural Transformation

Cite this Article: Mohamed Buheji and Dunya Ahmed, Optimising Constraints of 'Cave Syndrome' Fear of Coming Back to Normality, International Journal of Management (IJM), 12(9), 2021, pp. 84-92.

https://iaeme.com/Home/issue/IJM?Volume=12\&Issue $=9$

\section{INTRODUCTION}

The Covid-19 pandemic changed our life without proper introduction or choice. The great challenge for all humanity is our ability to set aside our fear and our desire to hold onto the status quo and step into the world of new possibilities that exist with transformation.

As the easing of lockdown or social distancing procedures begins after more than a year and the return to routines of some of the previous life practices, many people are experiencing fear of it is called 'Cave Syndrome'. This fear or syndrome is thought to be about going out of the comfort zone or fear of not being safe. In this paper, we try to investigate further, to see 
what are the sources of cave syndrome, and what type of checks and balances could be recommended to ease such essential transformation.

Fear of going out of what is perceived to be a new comfort zone is normal, as humans are naturally difficult to change after getting used to a certain norm for more than a few weeks, let alone more than 80 weeks, i.e., since the outbreak of the COVID-19 pandemic. What is not normal is our failure to alleviate or mitigate the consequences of this fear once it becomes chronic. Therefore, communities and government should not ignore the seriousness of the issue, the alarming fear after a long lockdown, if to avoid 'professional fatigue' or more new types of 'mental illnesses.

This work would touch base with the different 'resisting to return' to certain pre-new normal practices and would try to exploit lessons and opportunities learned from this. Buheji and Sisk (2020)

\section{LITERATURE REVIEW}

\subsection{Transformation and the New Normal}

Sardar (2021) argues that "new normal" is nothing more than a return to the status quo before COVID-19, with some extra's appendages. As it suggests that what lies at the other end of postnormal times is best seen as the domain of the transnormal. This domain is unique as it compensates between demands of capitalism, neoliberalism, modernity, and postmodernism. Buheji (2020b)

The route to a transformed world is a process of systematic movement leading to transposition. This transposition or transformation contains mainly acts of changing relationships, modified structures, and more emphasised values that interactively and collectively relocate humanity to a trans, or stable, state or realm of existence. The concepts of trans-modernity, and mutually assured diversity, are potential tools that could be investigated to navigate toward the transnormal and set the way out of post-normal times. Buheji (2020b)

Florida et al. (2021) see that this new normal affected cities structures and lifestyle; thus the longer it stays, the more it is difficult to go back to the previous model, unless again new transformation happens again. i.e., Communities needed re-learning, as the unlearning happened over time. For example, people with disabilities suffer from less stress during working from home. In addition, the new-normal open wide opportunities to join conferences, webinars and training online, in an easier way. Samuel (2021) concluded that the "normal" we are returning to, may not be so normal at all. It requires us to ask ourselves what we can do to prepare ourselves to change and manage or mitigate any negative impact highlighted by the pandemic.

\subsection{Sources of Fear}

Stephens (2020) found that media focus going back to normality in post-COVID-19 as hope and this affect many people emotions. A survey by Vox shows that people are nervous of returning to normality, as it means returning to stress and a specific quality of life requirement. The survey showed that there are two categories of groups that have fear. The first group is worried about 'doing things they have not done for a long time', while the second group they have even 'anxiety from issues that were hidden in pre-pandemic and became clearer during the pandemic'. They meant, for example, issues as the influence of work and stress on their mental health, Samuel (2021), da Silva et al. (2020).

In a recent study in the USA, more people were found to feel anxious about going back to normality as they have built this routine over a year, in addition to fear of diseases. While others see that pandemics bring them positive changes in their lifestyle, and they do not want to lose 
these advantages, Rodriguez (2021). The work of both Samuel (2021) and Rodriguez, (2021) give an analogy for fear of 'going back to normality' as fear of 'post-traumatic stress disorder' (PTSD), i.e., cannot be easily overcome without proper counselling.

\subsection{Why and How People Experience Fear during Transformations?}

The pandemic caused series of fear inputs that keep being generated by the transition period we are in. In times of the unknown, or uncertainty, humans tend to lean into fear as a default emotion. However, fear is tough as it is both a powerful motivator and a liar. It can significantly distort reality when dealing with other people, and this distortion might affect both ways. Studies show that a significant amount of our energy goes into understanding relationships. Our fear would be dissipated around how we manage our personal fears, the fears of the other party, and our collective fears. Therefore, these energy dissipation sources excite specific psychological elements and alarm the fear of the unknown or uncertainty. Buheji (2019)

The great challenge for all humanity is our ability to set aside our fear and our desire to hold onto the status quo and step into the world of new possibilities that exist with transformation. This was confirmed by a recent study by George, et al. (2020) where they found that fear is more linked to anxiety due to fear of change. However, fear is not so bad. In a recent study to investigate the link between worrying, thinking and problem-solving, by Carr and Szabó (2015), worrying was found to be a main construct of problem-solving.

Buheji (2021) shown, as per Figure (1), that fear of dealing or living with uncertainty (or not knowing) could be overcome by learning and having a clear meaning and purpose of life. Buheji sees that the association of excitements and challenges could lead to making many people accept to 'live uncertainty'. This requires that the employers or the concerned parties specify the area of fear, i.e., is it about mistrust, or creating excuses, vulnerability of the people. This is especially true if the people started to settle down with the new normal habit, i.e., now staying in the rest area (feeling safe and judging). This requires as per Buheji (2021b), unlearning and learning practices in order to deal with the challenges and the problems, or to live with uncertainty, or do more exploration. This could be a repeated counselling exercise till we reach the evolution area, i.e., the area where new goals or new life paradigm is shaped and where the acceptance of living in uncertainty would be much higher. Buheji (2019)

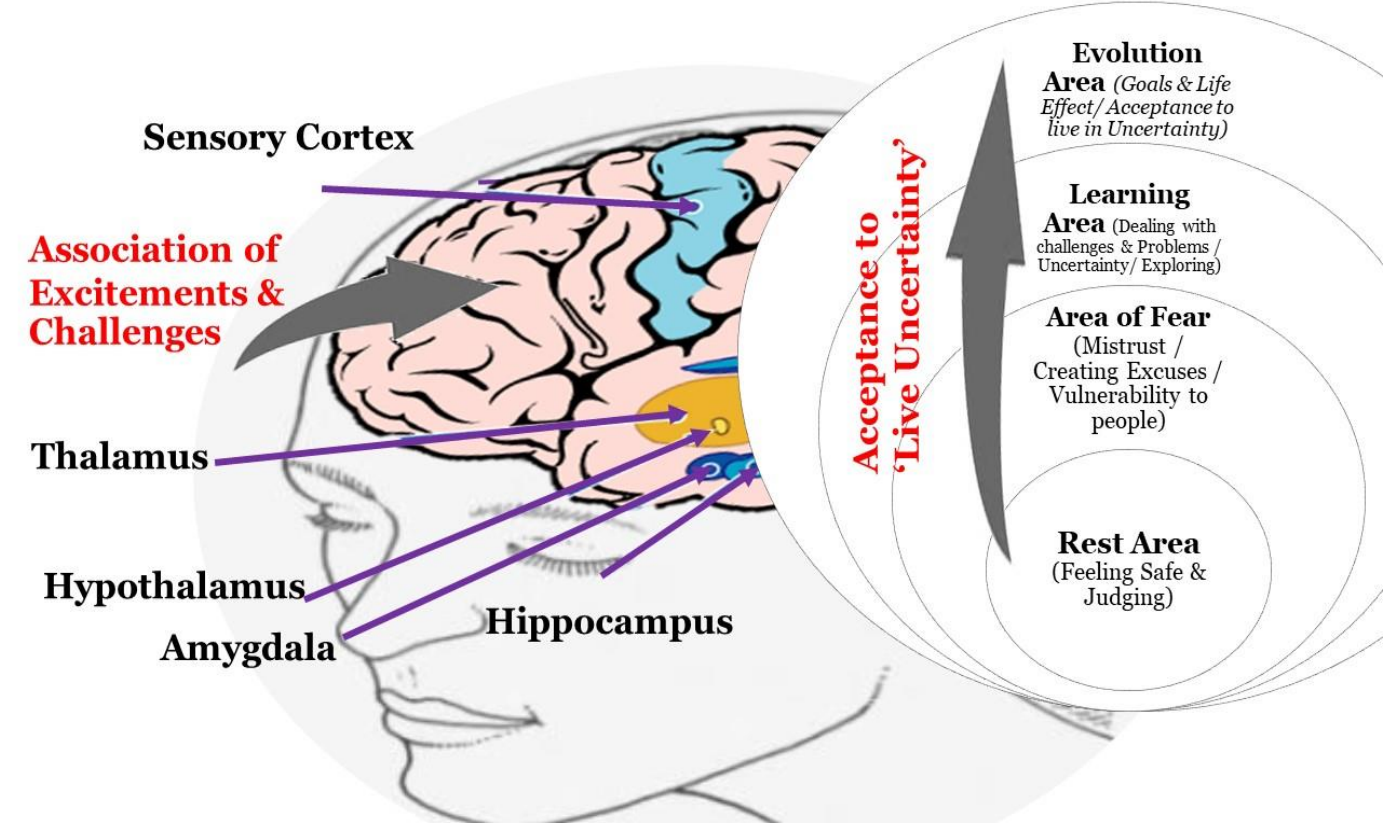

Figure 1 Represents the Physiology of Brain During Fear \& Uncertainty. 


\subsection{Habit Stacking}

When we link between the habits developed during the long lockdown in a period of more than 18 months, and we visualise the type of other habits of comfort zone stacked with it as a result of new discovery, or another point of interest, or due to spillovers of newly developed behaviour; we could see why people resist going back to work. Yarberry and Sims (2021).

The 'habit stacking' that happened needs to be linked to certain comfort with timing, location and socialisation issues which need to be investigated and explored per case. Realising the likelihood that certain habit stacking has been created over the last year and embedded to the existing behaviours would help dissect the causes of resistance and the management of change required for the individual or the community. There might be a certain collective habit stacked over time that needs to be realised if this habit can be generic. Scott (2014).

The time and location for a given behaviour related to the new habit stacked need to be exploited to manage any possible fear and panic. When we have enough realisation of the scale of the problem, i.e. how deep the new habits are stacked, we could take more factual based decisions of what alternatives we have for our employees, or targeted community. Scott (2014).

Once we know the particular influence of the new habit stacked, we can appreciate the negative imagination that creates fear of going back to pre-new normal, Buheji and Sisk (2020). Management of imagination is like mitigation of fire; we need to emphasise on what it can create, and rather mitigate what it can destroy. Doing something with fear, can make people act from the worst of themselves and with panic. Panic is beyond fear; it is where sanity is lost. Therefore, we need to make careful decisions supporting with counselling and assessment if we are to engulf the cave syndrome. Leotti (2021)

\subsection{The Post-Pandemic Mental Contagion}

Many people panic or are strained by fear when they feel small pains in their chests or experience some difficulty of breathing. This case is being repeated by different people whose diagnostic tests and check-ups are showing no serious conditions. Now many scientists believe that these repeated cases reflect the influence of the media on the mind subconscious thinking. People started to intensely imagine the symptoms they read or hear about and began to experience them in their bodies. This is called the pandemic mental contagion. Leotti (2021)

The mental contagion could cause serious panic attacks, driven by fear. Therefore, this type of contagion ought to be replaced, through counselling with a passion for a better life. The counselling should focus on how to calm that would overcome a fear of death. The counselling needs to embed or put seeds for a new hunger for life, or establish meaning for life, Buheji (2021). People need to see that they have been chosen to live this chapter of the human story. It is an era that is full of human new opportunities never experienced before. If we manage to engrain this in people's minds, we could overcome the mental contagion negative effects, as everyone would be busy with the amazing things waiting for them. Okri (2020)

Other approach for overcoming collective mental contagion is that each community, be it organisations or societies take a pause of how this pandemic and the generation-defining moment could reflect on creating or modifying new policies, or procedures, or tools that could change or radically improve the community status regarding important not well-addressed issues, Okri (2020). Just to give an example where the collective pauses and reflections could bring is where the community stand in climate change, bringing better healthier communication with its followers or customers, or contributing to the educational development to its people, or in the elimination of specific socio-economic issues as migration, unemployment, inequality, and poverty, etc. 


\subsection{Introduction to Cave Syndrome}

'Cave syndrome' is a description that came as a trend when people started to be worried, anxious about their return to the old way of doing things after getting used to the norms of the new normal. This phenomenon is found to affect people who are characterized to be feeling anxious or afraid about returning fully to the demand of work or society, even if fully vaccinated. Child Help (2020), George et al. (2020).

This syndrome comes as a result of long periods of lockdown created amplification in social anxieties. So far, there are not enough studies in the literature about the cave syndrome. However, it is highly expected that 'cave syndorme' be one of the hotest topics in the knowledge communities in the next few months, as more remote employees are hesitant to relinquish the safety and comfort of home workspaces. Marples (2021), Samuel (2021), Rodriguez (2021), Yarberry and Sims (2021).

Despite the scarcity of well-established studies, the media report that cave syndrome would be more common in younger people who experienced the pandemic caves and got limited exposure to what might be missing in the outside world. Fernstrom (2021), Stiefvater (2021).

\subsection{How Inspiration Economy Deal with Transformation Times}

Inspiration Economy (IE) is a concept that Dr Buheji developed in 2015 to help exploit opportunities within problems or challenges, Buheji (2016). Therefore, IE sees and publishes many papers on the opportunities brought by the pandemic and the new normal. Now, as many of the world communities are preparing to go back, IE sees that this transformation could bring a bundle of discoveries and inspiration currencies, if handled effectively.

In order for this transformation to happen, proper assessment of the resources collected, including the new habit stacking, needs to be dissected. Going back to pre-new normal transformation needs to filter the new capacities needed to compensate for the new competency demands that the pandemic brought, as per Buheji and Buheji (2020). i.e., how this transformation could emphasise habits relevant to the 5P's required for demanded competency in the contemporary, and foresighted future: proactiveness, preparedness, pull-together, problem-solving and publication. Which would complement and compensate for the type of resistance to change that would be represented by the capacity brought by the $5 \mathrm{R}$ 's; i.e. being able to react, realise, resolve, reshape and be resilient. Buheji and Buheji (2020), Buheji (2019).

Being able to create a formula from these relations through learning what is required for each case or each type of community would bring lots of profound knowledge about optimising the best collective policies, or solutions, or defining counselling approaches to ease this transformation to some of the pre-pandemic environment, Yarberry and Sims (2021). Also, this exercise would enhance the readiness and the reliability for future foresighted post-pandemic spillovers and challenges. Buheji (2020a), Buheji and Ahmed (2021), Buheji and Ahmed (2020)

\section{METHODOLOGY}

This paper used the integrative review method, which is a specific review method that summarizes past empirical or theoretical literature to provide a more comprehensive understanding of a particular phenomenon or problem, Broome (1993). As per the collective observations from the media and the literature review; the accumulated experience were reconstructed to build a new lifestyle that could help to enhance the preparedness for future emergency challenges. 


\section{EVALUATING ADVANTAGES AND DISADVANTAGES OF PANDEMIC ENFORCED CAVE PRACTICES}

This research tries to evaluate the sources of needs, wants and fears that pandemic social distancing, and lockdown from any changes that the new normal introduced in our lives and livelihood. Table (1) targets to bring new ideas, or reach blended decisions that would mitigate the fear or the cave syndrome negative impact on the mental health.

Table 1 Optimisation of COVID-19 Pandemic Advantages and Opportunities (to overcome Cave Syndrome)

\begin{tabular}{|c|c|c|}
\hline & Advantages & Disadvantages \\
\hline Family & Life balance & $\begin{array}{l}\text { Parents spend more time with distance } \\
\text { learning }\end{array}$ \\
\hline Children & $\begin{array}{l}\text { Closer to the parents \& more time with } \\
\text { them }\end{array}$ & Anxiety from distance learning \\
\hline Elderly & More time with family & $\begin{array}{l}\text { Less time with friends and activities } \\
\text { (i.e. worships places) }\end{array}$ \\
\hline Adults & More relax & Less activities \\
\hline People with disability & $\begin{array}{l}\text { More and easier access to activities } \\
\text { through webinars } \\
\text { More time with family }\end{array}$ & Less physical activities and gatherings \\
\hline Work & Focused on work & $\begin{array}{l}\text { Loneliness } \\
\text { Missing group discussions \& } \\
\text { motivation }\end{array}$ \\
\hline Environment & $\begin{array}{l}\text { Less transportation pollution } \\
\text { Less Office Space }\end{array}$ & \\
\hline Health & $\begin{array}{l}\text { Better mental health as a result of life } \\
\text { balance }\end{array}$ & $\begin{array}{l}\text { mental health problems as a result of } \\
\text { loneliness and anxiety of getting } \\
\text { infected } \\
\text { less movement } \\
\text { Long term affect for infected people }\end{array}$ \\
\hline Traffic & Less traffic & \\
\hline Economy & $\begin{array}{l}\text { Less need to live in central cities } \\
\text { Increase productivity } \\
\text { New jobs will come up }\end{array}$ & $\begin{array}{l}\text { Some will lose their jobs or business. } \\
\text { The rich people are getting richer. } \\
\text { People at middle class are } \\
\text { suffering with increased unemployment } \\
\text { rates. }\end{array}$ \\
\hline First liner & $\begin{array}{l}\text { More experience \& skills } \\
\text { More recognition }\end{array}$ & $\begin{array}{l}\text { Work pressure } \\
\text { Away from family }\end{array}$ \\
\hline
\end{tabular}

Suppose we optimize the constraints presented in Table (1). In that case, we can exploit many opportunities to bring a compromised counselling or policies guideline that extracts from both the pandemic lockdown advantages and disadvantages. These opportunities should help to bring a more resilient solution or resolution to those with cave syndrome. This requires adaptation with the realized advantages and a mindset that appreciates the post-new-normal. A new lifestyle could be developed as per each individual or community time and place. Buheji (2020a)

More solutions could come more effectively in further research if we study these optimized constraints from a purely socio-economic perspective only. Figure (1) below shows how the balance between socio-economic constructs changed during the pre- and during-and postpandemic, The propose of this is to strick a balance between these different periods as the transformation towards "normality" happens. 


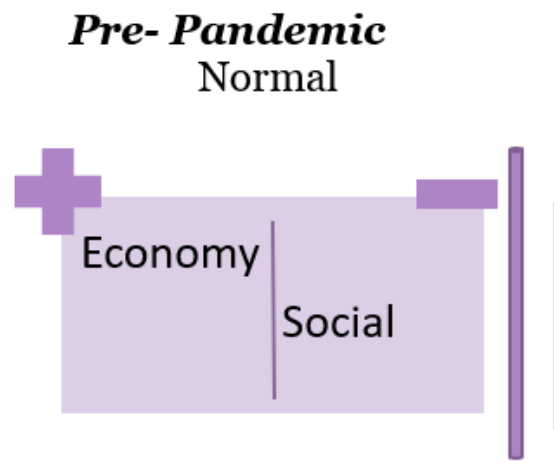

During Pandemic

New- Normal

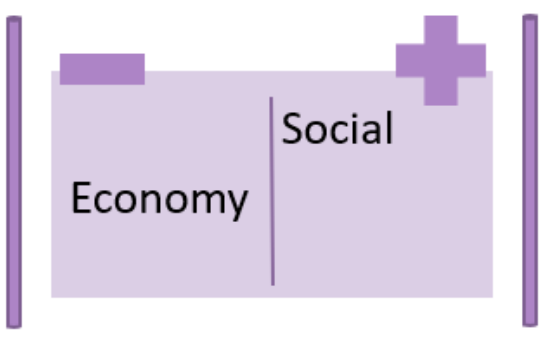

Post-Pandemic

Normality

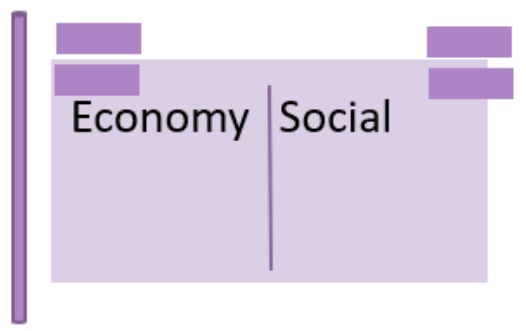

Figure 2 Socio-Economic Constraints Optimisation

\section{RECOMMENDATIONS \& CONCLUSION}

This paper targets to picture and give early solutions for this moment of history where people strive to overcome the impact of a devastating pandemic called COVID-19. Particularly, the researchers focused on the moments of fear, panic or resistance to go environment of prepandemic or prior to the new normal. Furthermore, the researchers focused on the transformation mechanisms that could help filter the qualities that could be exploited from the collective experiences of the last 18 months or so.

The paper's implication is that is open different alternatives that might need to be addressed or deployed through policies, decisions, or counselling, which would help overcome the cave syndrome. The visualization that these inspiration economies driven approaches is that this is a defining moment where communities could utilize and even optimize to the betterment of their historical development.

Therefore, this study recommends that returning to what was named normal "pre-covid", should be gradual, and without ignoring all the lessons learned from pandemic time, such as distance learning, working, e-trading, etc. For example, see where the blended lifestyle should be implemented in specific things and where things could be through distance.

The conclusion sets a framework that encourages further research to capture post-pandemic relations, relationships, and communication models that lead to a more mature work-life balance that overcomes the community's diversified conditions and their best fit mental health requirements. Besides these recommendations are not yet piloted, this paper has two limitations: first, not addressing the impact of the cave syndrome on productivity and not covering in detail the proposed solutions for overcoming the cave syndrome from a purely socio-economic perspective. The authors believe that this might be mainly due to the limitation of the scope of the paper.

\section{REFERENCES}

[1] Broome M. (1993) Integrative literature reviews for the development of concepts. In Concept Development in Nursing, $2^{\text {nd }}$ edition, (Rodgers B.L. \& Knafl K.A.). W.B. Saunders Co., Philadelphia, USA, pp. 231-250.

[2] Buheji, M (2021) Physiology of Inspiring Life, 'Realising How Inspiration Works in Our Bodies'. Westwood Books Publishing, USA. ISBN 978-1-64803-652-1.

[3] Buheji, M (2020a) Optimising 'Moments of Pauses' - A Reflections from COVID19 Pandemic, International Journal of Psychology and Behavioral Sciences, Vol. 10 No. 4, 2020, pp. 85-92. 
[4] Buheji, M (2020b) The New Normal - A New Era Full of Inspiration and Resilience after COVID-19, Forward from "Editor in Chief", International Journal of Inspiration \& Resilience Economy; 4(2): 0-0.

[5] Buheji, M (2019) Reviewing How 'Creating Resilient Economies' can Help Developing Countries in Uncertain Times, American Journal of Economics, Vol. 9, Issue 5, pp. 259-263.

[6] Buheji, M (2016) Handbook of Inspiration Economy Bookboon, London, UK. ISBN: 978-87403-1318-5.

[7] Buheji, M and Ahmed, D (2021) COVID-19 The Untapped Solutions, (Part 2), Westwood Books Publishing, USA. ISBN 978-1-64803-629-3

[8] Buheji, M; Ahmed, D (2020) 'Covid-19 The Untapped Solutions', (Part 1), Westwood Books Publishing LLC, USA. (Published in Sep 2020). ISBN- 978-1-64803-377-3

[9] Buheji M. and Buheji, A (2020) Planning Competency in the New Normal- Employability Competency in Post- COVID-19 Pandemic, International Journal of Human Resource Studies, $10(2), 237-251$.

[10] Buheji, M and Sisk, S (2020) You and The New Normal, AuthorHouse, UK.

[11] Buheji, M; Ahmed, Dunya and Jahrami, H (2020) Living Uncertainty in the New Normal, International Journal of Applied Psychology; 10(2): 21-31.

[12] Buheji, M; Jahrami, H; Dhahi, A (2020) Minimising Stress Exposure During Pandemics Similar to COVID-19, International Journal of Psychology and Behavioral Sciences, Vol. 10 No. 1, pp. $9-16$.

[13] Buheji, M and Ahmed, D (2017) Breaking the Shield- Introduction to Inspiration Engineering: Philosophy, Practices and Success Stories, Archway Publishing, from Simon \& Schuster, USA.

[14] Carr I. and Szabó M. (2015) Worry in Children: Changing Associations with Fear, Thinking, and Problem-Solving, The Journal of Early Adolescence, 35(1):120-135.

[15] Child Help (2020) COVID-19 'cave syndrome' - A survivor's guide https://www.childhelp.org/blog/covid-19-cave-syndrome-a-survivorsguide/\#: :text='Cave\%20syndrome'\%20describes\%20a\%20reluctance,anxieties\%20amplified $\% 20$ by $\% 20$ recent $\% 20$ solitude.

[16] da Silva. M; Rocha, R; Buheji, M; Jahrami, H and Cunha, K (2020) A systematic review of the prevalence of anxiety symptoms during coronavirus epidemics, Journal of Health Psychology, pp. $1-11$

[17] Fernstrom, M (2021) What is Covid 'cave syndrome' - and how to fix it, March 17, NBC. https://www.nbcnews.com/know-your-value/feature/what-covid-cave-syndrome-how-fix-itncna1267630

[18] Florida R, Rodríguez-Pose A, Storper M. (2021) Cities in a post-COVID world. Urban Studies. June.

[19] George, T., Hart, J. and Rholes, WS. (2020) Remaining in unhappy relationships: The roles of attachment anxiety and fear of change, Journal of Social and Personal Relationships, 37(5):1626-1633. 
[20] Leotti, S. (2021) The imaginative failure of normal: Considerations for a post-pandemic future. Qualitative Social Work, 20(1-2):200-205.

[21] Marples, M (2021) If 'cave syndrome' is keeping you from going in public, here's how to combat it, CNN, June 18, 2021. https://edition.cnn.com/2021/06/17/health/cave-syndrome-pandemicwellness/index.html

[22] Okri, B (2020) Fear of Covid-19 is a mental contagion - and that's something we can fight, The Guardian, March 26. https://www.theguardian.com/commentisfree/2020/mar/26/fear-of-covid19-is-a-mental-contagion-ben-okri

[23] Rodriguez, S. (2021) As the pandemic fades, some Americans are anxious about a return to normal, CNBC, MAR 20 2021.https://www.cnbc.com/2021/03/20/why-some-are-averse-toreturn-to-normal-post-covid.html

[24] Samuel, S. (2021), We shouldn't go back to “normal.” Normal wasn't good enough. Vox, 12 May. https://www.vox.com/future-perfect/22394635/anxiety-back-to-normal-covid-19pandemic

[25] Sardar Z. (2021) Afterthoughts: Transnormal, the "New Normal" and Other Varieties of "Normal" in Post normal Times. World Futures Review. July 2021.

[26] Scott, J (2014) Habit Stacking: 97 Small Life Changes That Take Five Minutes or Less, CreateSpace Independent Publishing Platform

[27] Stephens E. (2020) Post-normal: Crisis and the End of the Ordinary. Media International Australia. 2020;177(1):92-102.

[28] Stiefvater, S (2021) The 3-Word Phrase Everyone with Cave Syndrome Needs to Hear Right Now, July 1, Purewow.com https://www.purewow.com/wellness/cave-syndrome-phrase

[29] Yarberry S. and Sims C. (2021) The Impact of COVID-19-Prompted Virtual/ Remote Work Environments on Employees' Career Development: Social Learning Theory, Belongingness, and Self-Empowerment. Advances in Developing Human Resources ;23(3): 237-252. 